\title{
IDENTIFIKASI IKAN SAPU-SAPU (Loricariidae) BERDASARKAN KARAKTER POLA ABDOMENDI PERAIRAN CILIWUNG
}

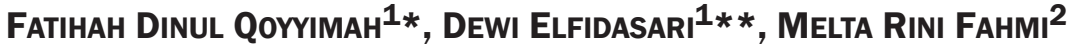 \\ 1 Program Studi Biologi, Fakultas Sains dan Teknologi, Universitas Al Azhar Indonesia. \\ *email: fatihahuai12@gmail.com; * *dewi.elfidasari@gmail.com \\ 2 Balai Penelitian dan Pengembangan Budidaya Ikan Hias, Pusat Penelitian dan Pengembangan Perikanan, \\ Kementrian Kelautan dan Perikanan. Kota Depok Jawa Barat
}

\section{INTISARI}

Ikan sapu-sapu (Loricariidae) merupakan invasive species yang terdapat pada beberapa negara, salah satunya Indonesia. Ikan tersebut dapat ditemukan pada sungai Ciliwung. Bagian hilir dari sungai tersebut adalah Kota Jakarta. Ikan sapu-sapu yang terdapat di Indonesia termasuk pada Genus Pterygoplichthys. Genus Pterygoplichthys masih sulit dibedakan berdasarkan karakter morfologi. Salah satu cara yang dapat dilakukan untuk mengidentifikasi ikan tersebut adalah melihat pola abdomen. Sampel yang digunakan berjumlah 28 ekor. Identifikasi berdasarkan pola abdomen yang dapat dilakukan dengan melihat literatur yang ada. Hasil penelitian yang dilakukan menunjukkan terdapat 2 spesies ikan sapu-sapu pada sungai Ciliwung dan jenis inter-grade. Spesies tersebut adalah Pterygoplichthys pardalis dan Pterygoplichthys disjunctivus.

Kata kunci: ikan sapu-sapu, Sungai Ciliwung, karakter morfologi, pola abdomen

\begin{abstract}
Suckermouth armored catfish is invasive species that can be found in some countries, one of them is Indonesia. The fish can be found on Ciliwung River. The downstream of Ciliwung River is Jakarta. Suckermouth armored catfish which can be found in Indonesia is Pterygoplichthys genus. Pterygoplichthys genus is still difficult to distinguished based on their morphological character. One way to identify the fish is by seeing its abdominal pattern. Samples used were 28 fishes. Identification based on abdominal pattern was done by using the literature. The result showed 2 species and one inter-grade species of suckermouth armored catfish on Ciliwung River. The species is Pterygoplichthys pardalis and Pterygoplichthys disjunctivus.
\end{abstract}

Keywords: sucker mouth armored catfish, Ciliwung River, morphological characteristic, abdominalis pattern

\section{PENDAHULUAN}

Ikan sapu-sapu merupakan salah satu jenis ikan yang termasuk dalam invasive species. Invasive species dapat menjadi predator maupun kompetitor terhadap spesies asli (Hill \& Lodge 1999), selain itu ikan ini dapat menyebabkan hibridisasi tidak terduga (Mallet 2007). Keberadaan ikan sapu-sapu dapat diketahui dari lubanglubang yang terlihat dalam bentuk kumpulan di sepanjang lereng pinggir sungai. Lubang tersebut berfungsi sebagai tempat peletakkan telur ikan (Nico et al. 2012).

Ikan sapu-sapu dapat ditemukan pada berbagai lokasi, salah satunya adalah sungai Ciliwung. Sungai tersebut merupakan aliran yang berasal dari Gunung Pangrango yang melewati Bogor, Depok, dan berakhir pada teluk Jakarta (Hendrawan, 2008). Sungai Ciliwung termasuk sungai di Indonesia yang paling banyak dimanfaatkan oleh masyarakat. Sungai Ciliwung merupakan salah satu sungai di dunia yang memiliki tingkat polusi sangat tinggi. Penyebab polusi terbesar di sungai tersebut adalah limbah domestik (International River Foundation, 2011).

Berdasarkan studi literatur yang dilakukan oleh (Wowor, 2010), pada tahun 1910 ditemukan 187 jenis ikan yang hidup pada DAS Ciliwung. Tahun 2009 hanya terdapat 20 jenis ikan dengan 5 jenis lainnya adalah jenis asing. Penurunan keanekaragaman jenis ikan di sungai Ciliwung tercatat mencapai $92,5 \%$ pada tahun 2010. Penurunan populasi ikan dapat disebabkan oleh beberapa faktor seperti pembangunan vila pada bagian hulu, pembangunan rumah dan kantor pada bagian tengah, sedangkan bagian hilir sudah tidak memiliki ruang terbuka hijau (Wibawa et al. 2010). Penurunan populasi ikan juga dapat disebabkan oleh keberadaan ikan sapu-sapu, karena tidak terdapat predator yang memakan ikan tersebut. Hal tersebut menyebabkan ikan sapu-sapu dapat mendominasi suatu wilayah perairan (Hadiaty, 2011).

Genus ikan sapu-sapu yang ada di Indonesia adalah Pterygoplichthys (Page dan Robins, 2006). Genus tersebut memiliki 22 spesies (Fishbase, 2015). 

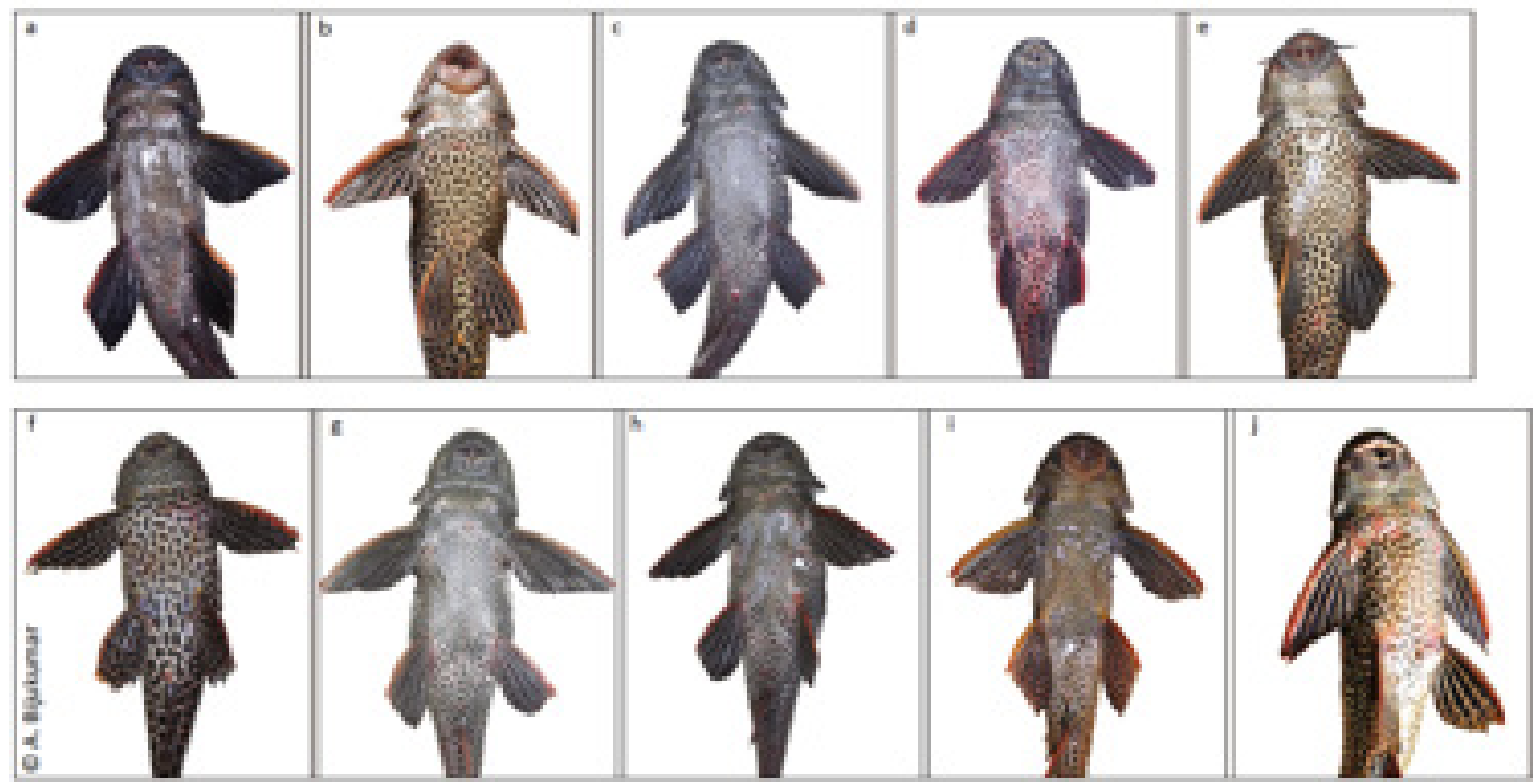

Gambar 1. Pola abdomen ikan sapu-sapu (a-b) P.pardalis, (c-h) inter-grades, (i-j) P.disjunctivus (Bijukumar et al. 2015).

Identifikasi terhadap ikan sapu-sapu dapat dilakukan dengan beberapa metode, yaitu melihat pola abdomen, morfometrik dan meristik (Bijukumar et al., 2015). Wu et al. (2011) melakukan pengelompokan dan identifikasi ikan berdasarkan morfologi serta molekuler. Data terkait identifikasi secara morfologi ikan sapu-sapu asal sungai Ciliwung masih terbatas. Penelitian ini dilakukan untuk mengidentifikasi ikan sapu-sapu di sungai Ciliwung berdasarkan pola abdomen.

\section{METODE PENELITIAN}

Penelitian dilakukan selama empat bulan, mulai dari bulan Agustus-November 2015. Objek penelitian adalah ikan sapu-sapu dengan ukuran antara 20,45-39,7 cm. Sampel diperoleh dari sungai Ciliwung daerah Rindam Jaya [6 ${ }^{\circ} 17^{\prime} 45.4^{\prime \prime} \mathrm{LS} 106^{\circ} 51^{\prime} 11.4$ "BT] sampai Bidara Cina [6 $6^{\circ} 13$ '53.4"LS $\left.106^{\circ} 51^{\prime} 49.4^{\prime \prime} \mathrm{BT}\right]$. Lokasi pengambilan sampel merupakan sungai berarus sedang dan landai, serta air sungai berwarna cokelat. Lokasi pengambilan sampel adalah kawasan terpanjang pada bagian hilir, yaitu $\pm 15 \mathrm{~km}$ dan melewati pusat kota Jakarta. Identifikasi objek dilakukan di Laboratorium Biologi Universitas Al Azhar Indonesia, Jakarta Selatan.

Alat yang digunakan pada penelitian ini adalah kontainer, penggaris dengan ketelitian $0,5 \mathrm{~mm}$, kamera, jaring penangkap ikan dan alat untuk penandaan (tagging). Bahan yang diperlukan dalam penelitian ini yaitu ikan sapu-sapu, kloroform dan pakan.

Tahap penelitian meliputi pengambilan sampel, pengelompokkan ikan berdasarkan pola abdomen dan identifikasi berdasarkan motif pada pola abdomen. Sampel ikan diambil secara acak dengan membeli pada penjual ikan sapu-sapu yang sedang mencari ikan di sepanjang aliran sungai Ciliwung. Ikan yang telah diambil dikelompokan berdasarkan pola abdomen. Pengelompokan dilakukan dengan melihat 2 literatur, yaitu Bijukumar et al. (2015) dan Wu et al. (2011) (Gambar 1 dan 2).

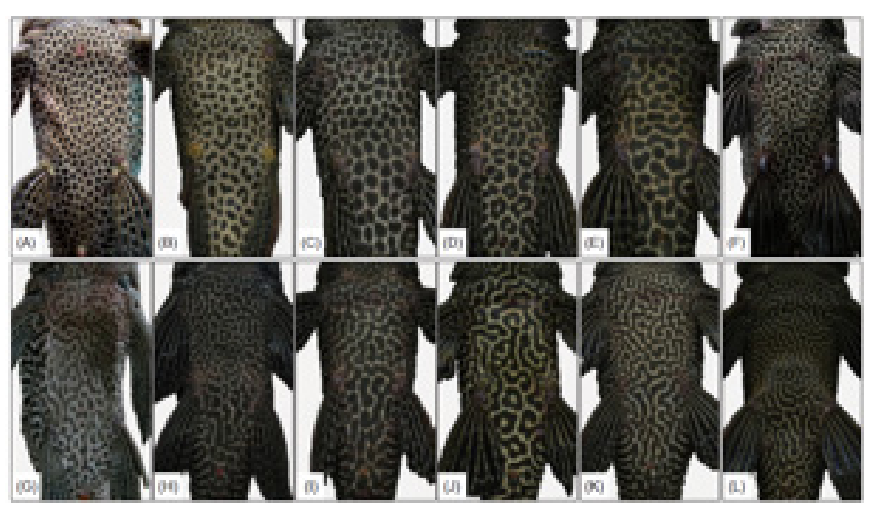

Gambar 2. Pola abdomen ikan sapu-sapu (a) P.pardalis dari Amazon, (b-c) P.pardalis dari Taiwan, (d-j) inter-grades, (k-l) P.disjunctivus (Wu et al. 2011).

Identifikasi Genus Pterygoplichthys dapat dilakukan dengan beberapa metode seperti melihat bentuk kepala, papilla, dan pola abdomen. Penelitian ini dilakukan dengan melihat pola abdomen yang merupakan karakter morfologi khas pada ikan ini. Hal tersebut disebabkan sampel memiliki ciri pola titik atau vermikulasi pada bagian ventralnya (Armbruster \& Page 2006). Berdasarkan pengamatan yang dilakukan dan hasil penelitian sebelumnya, terdapat kemiripan bentuk dan warna tubuh ikan sapu-sapu yang termasuk dalam Genus 

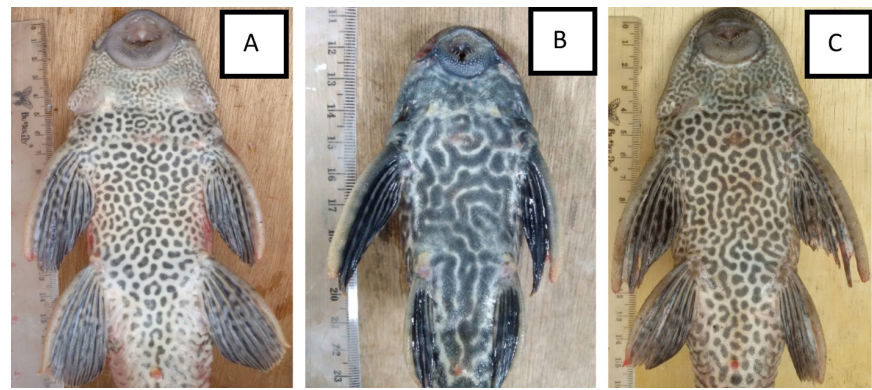

Gambar 3. Pola abdomen (a) P.pardalis, (b) P.disjunctivus, (c) inter-grade (Sumber : dokumentasi pribadi)

Pterygoplichthys, seperti P.anitsisi, P.multiradiatus, P.pardalis, dan P.disjunctivus. Hal ini menyebabkan masih terdapat kesulitan untuk melakukan identifikasi ikan sapu-sapu pada genus tersebut bila hanya melihat bentuk dan warna tubuhnya saja (Nico et al. 2012).

\section{HASIL DAN PEMBAHASAN}

Hasil identifikasi berdasarkan pola abdomen terhadap 28 sampel ikan sapu-sapu yang berhasil diperoleh pada penelitian ini menunjukan, $17,85 \%$ ikan termasuk pada spesies P.pardalis; 3,57\% merupakan spesies P.disjunctivus; sedangkan ikan lainnya sebanyak $78.58 \%$ termasuk pada spesies inter-grade (Gambar 3). Spesies inter-grade merupakan hasil hibridisasi antara dua spesies yang berbeda (Nico dan Martin, 2001). Nico et al. (2012) mengatakan bahwa sebagian besar populasi Pterygoplichthys yang didapat pada daerah Florida memiliki pola yang bercampur (inter-grade).

Penelitian yang dilakukan oleh $\mathrm{Wu}$ et al. (2011) mendapatkan hasil 2 hipotesis dan 1 spekulasi. Pertama P. disjunctivus kemungkinan merupakan spesies yang sama dengan P. pardalis. Hipotesis kedua yaitu populasi eksotik mungkin berasal dari hibridisasi diantara 2 spesies. Spekulasinya adalah spesies hybrid memiliki keunggulan adaptasi dibandingkan spesies non-hybrid. Apabila spekulasi tersebut benar maka hal itu yang menyebabkan jenis inter-grade lebih banyak dari 2 spesies lainnya.

Pengelompokan ini mengacu pada hasil penelitian yang dilakukan oleh Bijukumar et al. (2015) dan Wu et al. (2011). Bijukumar et al. (2015) melakukan identifikasi Pterygoplichthys berdasarkan pola abdomen, morfometrik dan meristik (Gambar 1), sedangkan $\mathrm{Wu}$ et al. (2011) melakukan pengelompokan dan identifikasi ikan berdasarkan morfologi serta molekuler (Gambar 2).

Page dan Robins (2006) mengatakan bahwa di Indonesia hanya terdapat 2 spesies ikan sapu-sapu, yaitu P.pardalis dan P.disjunctivus. Pola abdomen antara spesies P.pardalis dan P.disjunctivus terkadang sulit untuk dibedakan. Wu et al. (2011) mengatakan bahwa spesies P.pardalis memiliki pola abdomen titik-titik hitam (ada yang berbentuk seperti koma dan noktah); P.disjunctivus memiliki pola berlekuk-lekuk; sedangkan spesies Inter-grade memiliki pola gabungan diantara

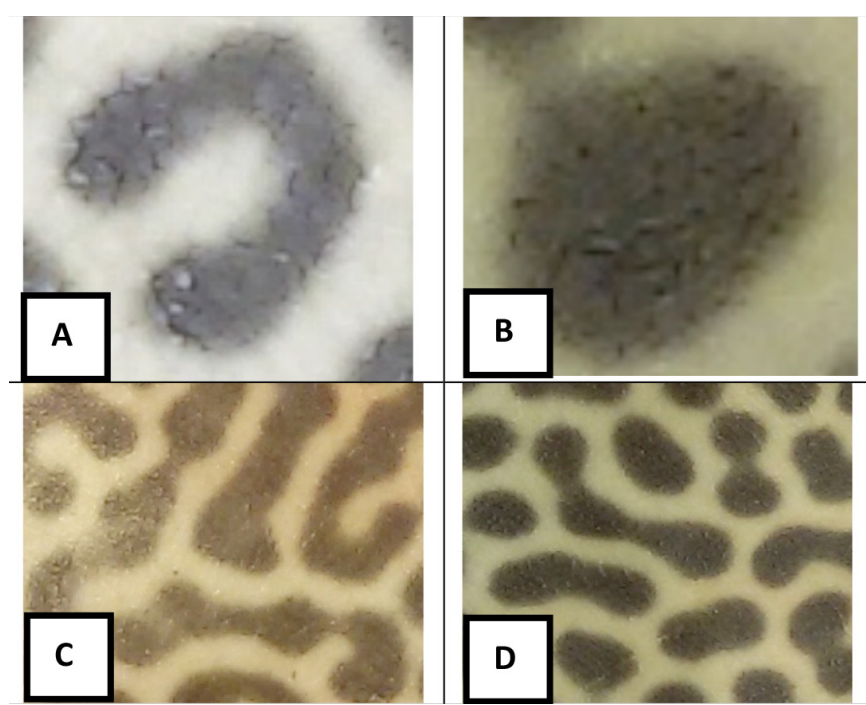

Gambar 4. Pola abdomen (a-b) Pterygoplichthys pardalis (c) Pterygoplichthys disjunctivus (d) inter-grade (Sumber : dokumentasi pribadi)

keduanya (Gambar 4). Spesies inter-grade atau hybrid pertama kali diidentifikasi pada tahun 2011. Apabila spekulasi Wu et al. (2011) yang mengatakan spesies inter-grade memiliki keunggulan adaptasi dibanding 2 spesies lainnya adalah benar, maka akan menyebabkan inter-grade lebih dominan dari yang lain.

Sebagai perbandingan, pada penelitian yang telah dilakukan di Florida ditemukan bahwa ikan Genus Pterygoplichthys yang diperoleh pada beberapa populasi di Florida memiliki pola warna yang bercampur. Beberapa individu memiliki pola titik-titik pada bagian ventralnya (sama seperti P.multiradiatus), beberapa ada yang memiliki pola ventral yang berlekuk-lekuk (sama seperti P. disjunctivus) dan yang lainnya memiliki pola yang tercampur antara titik-titik dan berlekuk-lekuk (Hybrid) (Nico et al., 2012).

\section{SIMPULAN}

Hasil identifikasi berdasarkan pola abdomen menunjukan terdapat dua spesies, yaitu Pterygoplichthys pardalis dan Pterygoplichthys disjunctivus serta terdapat ikan inter-grade. P. pardalis yang didapat berjumlah 5 individu, P.disjunctivus 1 individu, sedangkan 22 individu lainnya merupakan inter-grade. Penelitian selanjutnya dapat dilakukan secara molekuler untuk memastikan kebenaran dari spesies ikan sapu-sapu.

\section{UCAPAN TERIMA KASIH}

Terimakasih kepada Universitas Al Azhar Indonesia yang telah memberi dana Penelitian Grant UAI 2015 melalui Lembaga Penelitian dan Pengabdian Masyarakat (LP2M) UAI berdasarkan Surat Perjanjian Kerja Internal Pelaksanaan RE TA 2015 No. 005/SPK/A-01/UAI/ III/2012, sehingga penelitian ini dapat terlaksana dengan baik. 
Kepada seluruh jajaran TNI Kodam Jaya, khususnya Bapak Letjen. Agus Sutomo (mantan Panglima Kodam Jaya/Dankodiklat TNI), Bapak Mayjen TNI Teddy Lhaksamana (Panglima Kodam Jaya), Bapak Kol. Inf. Arudji Anwar (Aster Kasdam Jaya), Bapak Letkol. Czi. Edi Martadinata (Pabandya Bhakti Sterdam Jaya), Bapak Letkol. Inf. Firdaus Agustiana (Dandim Jakarta Selatan), serta para personil TNI selaku operator LCR dan pendamping di lapangan, terima kasih yang sebesarbesarnya atas dukungan, bantuan, dan kerjasamanya selama kegiatan sampling di sepanjang aliran sungai Ciliwung (Agustus-November 2015).

\section{KEPUSTAKAAN}

Armbruster, JW, Page, LM. 2006. Redescription of Pterygoplichthys punctatus and description of a new species of Pterygoplichthys (Siluriformes: Loricariidae). Neotropical Ichthyology 4(4):401-409.

Bijukumar A, Smrithy R, Sureshkumar U, George S. 2015. Invasion of South American suckermouth armoured catfishes Pterygoplichthys spp. (Loricariidae) in Kerala, India-a case study. J. of Threatened Taxa 3:6987-6995.

Fishbase. 2015. Scientific names where Genus equals Pterygoplichthys. [Online], Available:"http://fishbase.org/Nomenclature/ScientificNameSearchList. php?crit1_fieldname $=$ SYNONYMS.SynGenus\&crit1 field type $=$ CHAR\&crit1_operator $=$ EQUAL\&crit 1 value $=$ pterygoplichthys\&crit2_fieldname $=$ SYNONYMS. SynSpecies"[14 Desember 2015].

Hadiaty, RK. 2011. Diversitas dan hilangnya jenis-jenis ikan di sungai Ciliwung dan Sungai Cisadane. Berita Biologi 10(4):491-504.
Hendrawan, D. 2008. Kualitas air sungai Ciliwung ditinjau dari parameter minyak dan lemak. J.Ilmu-Ilmu Perairan dan Perikanan Indonesia 15(2):85-93.

Hill, AM dan Lodge, DM. 1999. Replacement of resident crayfishes by an exotic crayfish: the roles of competition and predation. Ecol. App. 9(2):678-690.

International River Foundation. 2011. Help Save The Ciliwung River Indonesia. [Online] Available:"http:// www.riverfoundation.org.au/event.php? $\mathrm{e}=1289$ " [10 September 2015].

Mallet, J. 2007. Hybrid speciation. Nature 446:279-283.

Nico, LG. 2012. Discovery of South American suckermouth armored catfish (Loricariidae, Pterygoplichthys spp.) in the Santa Fe River drainage, Suwannee River Basin, USA. Bioinvasions Records 1(3):179-200.

Nico, LG dan Martin, RT. 2001. The South American armored catfish, Pterygoplichthys anisitsi (Pisces: Loricariidae), in Teas, with comment on foreign fish introduction in the American Southwest. The Southwestern Naturalist 46(1):98-104.

Page, LM. dan Robins, RH. 2006. Identification of sailfin catfishes (Teleostei:Loricariidae) in South-Eastern Asia. The Raffles Bulletin of Zoology 54:455-457.

Wibawa, WD, Hardjomidjojo, H, Irianto G, Pramudya, B. 2010. Design pengembangan Holtikultura tahunan berkelanjutan di DAS Ciliwung Hulu. J. Hort. 20(2): 138-147.

Wowor, D. 2010. Studi Biota Perairan dan Herpetofauna di Daerah Aliran Sungai (DAS) Ciliwung dan Cisadane: Kajian Hilangnya Keanekaragaman Hayati, Cibinong: Pusat Penelitian Biologi Lembaga Ilmu Pengetahuan Indonesia.

Wu, LW, Liu, CC dan Lin, SM. 2011. Identification of exotic Sailfin Catfish species (Pterygoplichthys, Loricariidae) in Taiwan based on morphology and mtDNA sequences. Zoological Studies 50: 235-246. 